Article

\title{
Stump and Root Biomass of Poplar Stands
}

\section{Tord Johansson * and Birger Hjelm}

Department of Energy and Technology, Swedish University of Agricultural Sciences, Uppsala 75007, Sweden; E-Mail: birger.hjelm@slu.se

* Author to whom correspondence should be addressed; E-Mail: tord.johansson@slu.se; Tel.: +46-18-673830; Fax: +46-18-673156.

Received: 27 February 2012; in revised form: 18 March 2012 / Accepted: 23 March 2012 /

Published: 18 April 2012

\begin{abstract}
Today there is an increasing demand for biomass for use in energy production. In this study we investigated stumps and roots from six poplar (Populus sp.) stands growing on former farmland in Sweden, situated between latitudes 55 and $60^{\circ} \mathrm{N}$. The mean age of the poplar was 20 years (range 16-23), the mean stand density 1151 stems ha ${ }^{-1}$ (range 361-3279), and the mean diameter at breast height (over bark) $288 \mathrm{~mm}$ (range 81-574). All poplar stands were on clay soils (light and medium clay and light clay tills). The mean dry mass weight of the 72 excavated stumps was $45 \pm 39 \mathrm{~kg}$ (range 1-185), with the roots $\geq 50 \mathrm{~mm}$ weighing $14 \pm 16 \mathrm{~kg}$ (range 0.2-87). Dry mean stump weight represented $21 \%$ (by dry weight) of the stem. The mean total dry weight per hectare for stumps amounted to $34.9 \pm 21.8$ (range 12.9-66.9) tons and the equivalent value for roots was $12.0 \pm 9.6$ (range 4.7-10.9) tons. The excavation of below-ground biomass can either focus on the stump or the stump and parts of the root system. Depending on the combination of soil type and soil moisture the weight of soil adhering to stumps and the cleaning requirements will vary.
\end{abstract}

Keywords: basic density; biomass equation; excavation; poplar; root; stump

\section{Introduction}

Poplars belong to the genus Populus which, like Eucalyptus and Salix, grows rapidly and is widely used in intensive wood production systems. Poplar could easily be agamic propagated. Genetic selection and improvement of growth capacity and healthy individuals have been very efficient. They 
can be grown for biomass production, as carbon sinks to mitigate carbon dioxide production and for buffering against nutrient leakage. At the beginning of the 1900s the first industrial poplar plantations were established in Italy [1]. Natural hybrids of native and North American species were the most commonly planted trees. Plantations are usually established on fertile soils with rotation periods of 10-15 years and a spacing of $4 \times 4 \mathrm{~m}$ [2]. The rotation period of poplar plantations, however, is dependent on the initial plant density and growth rate [3].

In Sweden, fast-growing tree species, especially broadleaves (Salix clones, hybrid aspen and hybrid poplar) have been planted on former farmland [4]. Various studies of the above ground biomass produced by different species have been undertaken. Promising species for short rotation systems in Sweden include Salix clones, hybrid aspen and hybrid poplar [4]. An equation for calculating poplar aboveground biomass production has recently been published [5].

Poplar stumps are removed after tree felling as a way of avoiding the risk of pathogen attacks on seedlings in the new plantation [6]. After harvesting a poplar stand there are at least two alternatives for the site:

(1) Utilize the sprouting capacity of the poplar stumps. The sprouts can be harvested in a 5-10 years rotation or thinned leaving only one sprout per stump for later harvest of pulp wood.

(2) Extract the stumps with or without parts of the root system to allow subsequent re-planting of trees or cultivation of cereals.

As there is an increasing interest in poplar plantations for different purposes, more information about among others the stump and root biomass including the root distribution below ground is needed. However, as far as we know, there have, to date, been few studies quantifying poplar stump biomass especially in Nordic countries. After harvest of a poplar stand followed by stump excavation information about stump biomass and root distribution is needed for dimension of excavation efforts.

The aim of the present study was to measure the biomass of poplar stumps and parts of their root system. Biomass estimation functions were determined on the basis of data collected from clear cut poplar plantations on former farmland. We were able to draw some conclusions about the practical implications.

\section{Materials and Methods}

\subsection{Study Site}

The study evaluated six poplar stands growing on former farmland located between latitudes 56 and $60 \mathrm{~N}$ in Sweden (Figure 1 and Table 1). These stands are among the first poplar stands in Sweden to be planted in the period when farmland was reforested at the end of the 1980s, and which have been clear cut or thinned. Early growth and damage to the plantations were assessed on the basis of information provided by the forest owner. The age of the stands ranged from 16-23 years. The stands were clear cut (3) or thinned (3) near the beginning of the study period. 
Figure 1. Locations of the study sites, all on abandoned farmland in Sweden.

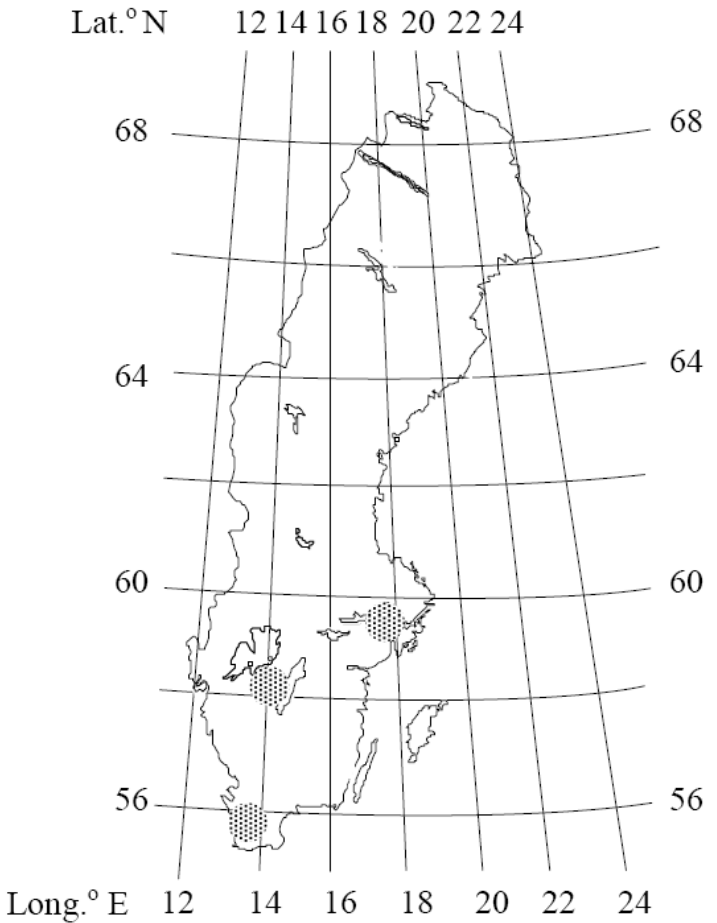

Table 1. Main characteristics of hybrid poplar stands growing at six locations in Sweden.

\begin{tabular}{|c|c|c|c|c|c|c|c|}
\hline $\begin{array}{c}\text { Location } \\
\text { no. }\end{array}$ & $\begin{array}{l}\text { Age, } \\
\text { years }\end{array}$ & $\begin{array}{c}\text { DBH, mm } \\
\text { Mean } \pm \text { SD }\end{array}$ & $\begin{array}{l}\text { Height, m } \\
\text { Mean } \pm \text { SD }\end{array}$ & $\begin{array}{c}\text { No. of } \\
\text { stems ha }^{-1}\end{array}$ & $\begin{array}{c}\text { Basal area } \\
\mathbf{m}^{2} \mathbf{h a}^{-1}\end{array}$ & Soil type & Variety ${ }^{(1)}$ \\
\hline \multirow[t]{2}{*}{1} & 21 & $353 \pm 81$ & $29.2 \pm 2.0$ & 361 & 30.9 & Light clay & - \\
\hline & & $119-574$ & $21.6-32.9$ & & & & \\
\hline \multirow[t]{2}{*}{2} & 23 & $210 \pm 70$ & $22.0 \pm 3.3$ & 632 & 19.1 & Light clay & 1 \\
\hline & & $81-372$ & $12.1-25.8$ & & & & \\
\hline \multirow[t]{2}{*}{3} & 16 & $140 \pm 51$ & $21.0 \pm 1.3$ & 3279 & 42.9 & Light clay & 2 \\
\hline & & $32-235$ & $13.1-22.4$ & & & & \\
\hline \multirow[t]{2}{*}{4} & 19 & $268 \pm 46$ & $25.1 \pm 1.1$ & 1250 & 59.4 & Medium clay & 2 \\
\hline & & $68-431$ & $19.2-27.0$ & & & & \\
\hline \multirow[t]{2}{*}{5} & 19 & $281 \pm 40$ & $24.0 \pm 0.7$ & 675 & 37.8 & Medium clay tills & 2 \\
\hline & & 194-356 & $22.8-25.0$ & & & & \\
\hline \multirow[t]{2}{*}{6} & 20 & $283 \pm 40$ & $25.8 \pm 1.1$ & 707 & 35.0 & Medium clay & 2 \\
\hline & & $197-367$ & $23.0-27.7$ & & & & \\
\hline Mean \pm SD & $20 \pm 2$ & $288 \pm 108$ & $25.3 \pm 4.1$ & $1151 \pm 1082$ & $37.5 \pm 13.4$ & - & - \\
\hline Range & $16-23$ & $81-574$ & $12.1-32.9$ & $361-3279$ & $19.1-59.4$ & - & - \\
\hline
\end{tabular}

${ }^{(1)}$ Clones of poplar species: 1. P. trichocarpa; 2. OP-42 (P. maximowiszii $\times$ P. trichocarpa).

\subsection{Characteristics of the Study Stands}

The number of stems per hectare was calculated before clear cutting or thinning operations. The stem number calculation was based on the number of stems on the planted area (0.1-1.0 ha). The outer row of trees in the stand was not included in order to avoid edge effects caused by factors such as wind, open areas, ditches and shading by adjacent stands. The diameter at breast height (DBH) of each 
counted tree was measured by cross callipering (Table 1), and the arithmetic mean diameter was calculated for each stand. In order to calculate the mean height of the stands, a statistical regression model for each stand was constructed. The height and diameter of nine trees in each of two subsample plots was measured. The location of the two subsample plots ( 3 trees in 3 rows close to each other) was selected systematically e.g., the first measured tree was the fifth tree in the third row. The other subsample plot was located in the opposite part of the stand, on a diagonal from the first plot. A regression model for each stand, describing the relationship between height and diameter, was produced. Tree mean height in the plots was calculated using the regression models.

\subsection{Dry Mass Estimations of Stumps and Roots}

The measurements were made in August when the poplars have leaves. There were some restrictions imposed by the owners relating to the maximum number of stumps that could be removed and their location. The main issues were: the risk of the excavator damaging the remaining stems and roots in the thinned stands; and the risk of damaging the stumps in the clear cut, thus reducing future sprouting ability. In each of the six stands 12 trees were evaluated prior to felling and their stumps excavated after felling. Because of the restrictions imposed, the trees had to be sampled in a strip around the stand as close as possible to the edge (within $\approx 5 \mathrm{~m}$ ). After initial recording of stems and stem diameter in the stands, the trees were divided into four diameter classes, representing the diameter distribution of the stand. Three trees representing each diameter class were selected for harvesting. Trees growing immediately adjacent to the stand edge were avoided to minimize the risk of light and temperature influences on the growth or root distribution pattern. Trees growing close to each other were not selected as their roots might have been affected by competition. The trees selected were healthy, without visible damage or fungal infestation. The presented results refer to restricted selections of samples. As the sampled individuals are representatives of division in diameter classes in the stand the results will be close to a healthy poplar stand in general.

Stump biomass was defined as "the stump proper above the ground and its direct continuation below ground and the root biomass as the side roots or laterals" [7]. During measurement of the diameter of the sample trees (Table 2) the stumps were marked in red with a number. Based on stem diameter, total aboveground biomass for individual poplar trees and total stem biomass were estimated using the biomass equation of Johansson and Karačić [5]. After this, the stands were either thinned or clear cut. Later the stumps (72 in total) were identified and the diameter of the stumps was recorded (Table 3). An excavator was used to remove the stumps. The excavation was undertaken carefully, with roots exposed manually using spades and the stump lifted out by the excavator. All roots were then removed from the stump, which was cleaned before weighing. The fresh weight of the stump was recorded in the field. The roots were cut and separated into three diameter classes: $>20 \mathrm{~cm}, 10-20 \mathrm{~cm}$ and $5-10 \mathrm{~cm}$. The length and fresh weight of the roots in each diameter class were recorded. 
Table 2. Characteristics of poplars used in the study.

\begin{tabular}{|c|c|c|c|c|}
\hline \multirow{2}{*}{ Location no. } & \multirow{2}{*}{$\begin{array}{c}\text { Diameter, mm } \\
\text { Breast height }\end{array}$} & \multirow{2}{*}{$\begin{array}{c}\text { Height, m } \\
- \\
\end{array}$} & \multicolumn{2}{|c|}{ Biomass, above ground, kg d.w. ${ }^{(1)}$} \\
\hline & & & Total $^{(2)}$ & Stem \\
\hline \multirow[t]{2}{*}{1} & $355 \pm 77$ & $26.7 \pm 1.6$ & $525 \pm 318$ & $399 \pm 245$ \\
\hline & $255-509$ & $24.4-29.6$ & $292-1270$ & $177-970$ \\
\hline \multirow[t]{2}{*}{2} & $210 \pm 64$ & $20.6 \pm 2.7$ & $160 \pm 112$ & $122 \pm 85$ \\
\hline & 119-327 & $15.6-23.2$ & $36-428$ & $28-326$ \\
\hline \multirow[t]{2}{*}{3} & $141 \pm 39$ & $19.2 \pm 1.3$ & $61 \pm 39$ & $46 \pm 30$ \\
\hline & $88-216$ & $15.3-21.4$ & $17-154$ & $13-118$ \\
\hline \multirow[t]{2}{*}{4} & $265 \pm 104$ & $25.3 \pm 2.7$ & $318 \pm 227$ & $243 \pm 173$ \\
\hline & $79-415$ & $19.8-27.5$ & $13-769$ & $10-587$ \\
\hline \multirow[t]{2}{*}{5} & $282 \pm 23$ & $24.3 \pm 0.3$ & $302 \pm 57$ & $230 \pm 43$ \\
\hline & 232-306 & $23.3-24.7$ & $184-363$ & $140-277$ \\
\hline \multirow[t]{2}{*}{6} & $288 \pm 62$ & $27.6 \pm 1.7$ & $336 \pm 166$ & $257 \pm 127$ \\
\hline & 189-376 & $24.7-29.8$ & $111-603$ & $85-460$ \\
\hline Mean \pm SD & $257 \pm 93$ & $23.9 \pm 3.6$ & $284 \pm 228$ & $216 \pm 174$ \\
\hline Range & 79-344 & $14.6-32.5$ & $13-1270$ & 10-970 \\
\hline
\end{tabular}

${ }^{(1)}$ Estimated by Johansson and Karačić [5]; (2) Total: stem + branches + leaves.

Table 3. Fresh and dry mass production $(\mathrm{kg})$ and mean percentage of total stump and root weight.

\begin{tabular}{cccccccc}
\hline \multirow{2}{*}{$\begin{array}{c}\text { Location } \\
\text { no. }\end{array}$} & Stump diameter, & \multicolumn{3}{c}{ Fresh weight, kg } & \multicolumn{3}{c}{ Dry weight, kg } \\
\cline { 3 - 7 } & mm & Total & Stump & Roots & Total & Stump & Roots \\
\hline 1 & $406 \pm 91$ & $241 \pm 117$ & $184 \pm 83$ & $57 \pm 44$ & $115 \pm 49$ & $89 \pm 36$ & $26 \pm 17$ \\
2 & $238 \pm 75$ & $61 \pm 57$ & $44 \pm 37$ & $17 \pm 22$ & $28 \pm 25$ & $21 \pm 17$ & $7 \pm 8$ \\
3 & $158 \pm 44$ & $27 \pm 20$ & $20 \pm 14$ & $7 \pm 6$ & $10 \pm 7$ & $8 \pm 6$ & $2 \pm 2$ \\
4 & $302 \pm 121$ & $172 \pm 168$ & $117 \pm 115$ & $55 \pm 57$ & $79 \pm 73$ & $54 \pm 51$ & $25 \pm 24$ \\
5 & $329 \pm 22$ & $150 \pm 38$ & $120 \pm 27$ & $30 \pm 18$ & $62 \pm 15$ & $50 \pm 10$ & $12 \pm 7$ \\
6 & $328 \pm 92$ & $157 \pm 91$ & $121 \pm 71$ & $36 \pm 24$ & $67 \pm 31$ & $52 \pm 24$ & $15 \pm 8$ \\
\hline Mean \pm SD & $294 \pm 109$ & $133 \pm 117$ & $99 \pm 85$ & $34 \pm 37$ & $59 \pm 52$ & $45 \pm 39$ & $14 \pm 16$ \\
Range & $87-587$ & $2-621$ & $2-420$ & $0.4-201$ & $1-291$ & $1-185$ & $0.2-87$ \\
\hline & & \multicolumn{2}{c}{ Percentage of total fresh weight } & Percentage of total dry weight \\
\hline Mean \pm SD & & - & $76 \pm 10$ & $24 \pm 10$ & - & $76 \pm 11$ & $24 \pm 11$ \\
Range & & - & $43-95$ & $5-57$ & - & $40-96$ & $4-54$ \\
\hline
\end{tabular}

\subsection{Basic Density Analysis}

Samples of wood from the trees, stumps and roots were collected to use for estimating basic wood density. A small section of stem surface at $4 \mathrm{~m}$, including the pith was taken. On the stump a small section of the cut surface, including the pith out to the outer part of the stump, was taken. Two samples of disks from the roots were taken: one in the 110-200 $\mathrm{mm}$ root class and one in the 50-100 mm class. 


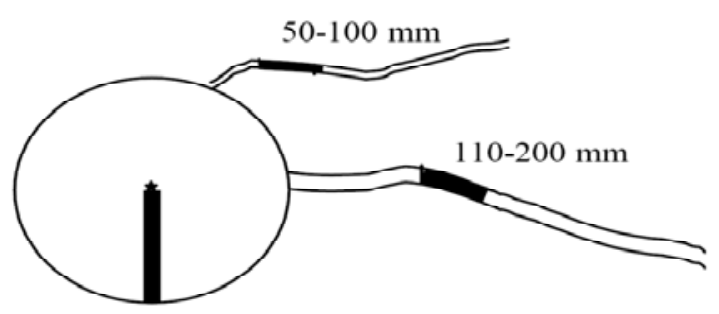

The basic density of stumps and roots was estimated using the water-immersion method described by Andersson and Tuimala [8]. Samples of stumps and roots were saturated in water for $24 \mathrm{~h}$ and then weighed and their volume $\left(\mathrm{cm}^{3}\right)$ determined. The proportion dry matter content of the wood $(\mathrm{g})$ in the samples was determined after drying at $105{ }^{\circ} \mathrm{C}$ in an air-ventilated oven for 3-5 days, depending on sample dimensions. Dry weight to fresh volume ratios of the debarked stumps and roots were then calculated as basic density $\left(\mathrm{g} \mathrm{cm}^{-3}\right.$; Table 4$)$. Using the dry weight of stump and root samples, their dry masses as a percentage of total dry weight of stump + roots were calculated' (Table 3 ). Dry mass as a percentage of fresh weight was also calculated based on the sample data.

\subsection{Soil Analysis}

Soil samples down to a depth of $30 \mathrm{~cm}$, were taken from two points in each stand, and the mean texture of the sampled layer was determined. Soils were classified as tills or sediments [9] in the field, following guidelines provided by Ekström [10] and then according to particle size in the laboratory. The particle size distribution was determined using a mechanical sieving method (English and German standard), and soil types were classified as follows: sediments as gravel $(20-2 \mathrm{~mm})$, coarse sand $(2-0.2 \mathrm{~mm})$, fine sand $(0.2-0.02 \mathrm{~mm})$, silt $(0.02-0.002 \mathrm{~mm})$ or clay $(<0.001 \mathrm{~mm})$; tills as gravel, sandy, silty, fine sandy or silty tills; and organogenic soils as moorland peat or moss peat. The soil samples contained particles of different sizes, but could be classified using one or two prefixes to indicate less frequent soil types. Clay soils were classified based on their percentage clay as follows: light clay (13-29\%), medium clay (30-40\%), heavy clay (41-60\%), and till clay (13-60\%). Most of the five stands were growing on sediments, namely light clay soil (3) or medium clay soil (2), and one on medium clay till (Table 1).

\subsection{Data Analyses}

The dry mass production per stump and root system was calculated on the basis of an equation describing the correlation between DBH and dry mass production $(\mathrm{kg})$, derived from data collected from all of the measured stump and root systems.

A power function was tested:

$$
M=\beta_{0} D^{\beta 1}
$$

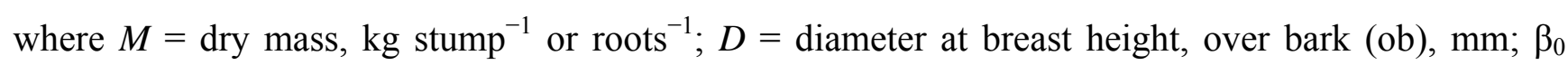
and $\beta_{1}$ are parameters.

The power model is frequently used to describe such relationships [9,11-14].

Based on the mean DBH, the actual dry mass production of each of the poplar stands included in the study was estimated. 
Data were analyzed by nonlinear regression using the SAS/STAT system for personal computers [15]. The fit of the nonlinear regressions was assessed on the basis of the coefficient of determination [16]:

$$
\mathrm{R}^{2}=1-(\mathrm{SSE} / \mathrm{SST}(\text { corrected }))
$$

where

$$
\mathrm{SSE}=\sum_{i=1}^{n}\left(w_{i}-\bar{w}_{i}\right)^{2}
$$

and

$$
\mathrm{SST}=\frac{1}{n} \sum_{i=1}^{n}\left(w_{i}-\hat{w}_{i}\right)^{2}
$$

The regression was also tested by root mean squared error (RMSE):

$$
\operatorname{RMSE}=\sqrt{\sum_{i=1}^{n} \frac{\left(w-\hat{w}_{i}\right)^{2}}{n}}
$$

$w_{i}, \bar{w}_{i}$ and $\hat{w}_{i}$ are observed, mean and predicted weights $(w)$.

Throughout the study, means are presented together with their associated standard deviation (SD).

\section{Results}

\subsection{Dry Mass Function for Stumps and Roots}

The tested function (1) fitted the data relating dry mass to DBH for both small and large hybrid poplar stumps and roots and the curves described by the function were statistically acceptable. The value of the coefficient of determination $\left(\mathrm{R}^{2}\right)$ and RMSE indicated a good correlation between the fitted curves and the estimated values. Further information about coefficient estimates is presented in Table 4.

Table 4. Estimated coefficients of equation (1) for dry weight estimations of poplar stumps and roots growing on former farmland.

\begin{tabular}{ccccccc}
\hline Components & Coefficient & Coefficient estimates & $\begin{array}{c}\text { Standard errors } \\
\text { of coefficient }\end{array}$ & $\mathbf{R}^{2}$ & $\mathbf{R M S E}$ & $\mathbf{P r}>\mathbf{F}$ \\
\hline \multirow{2}{*}{ Stump } & $\beta_{0}$ & 0.000116 & 0.000096 & 0.93 & 15.9123 & $<0.0001$ \\
& $\beta_{1}$ & 2.290300 & 0.140200 & & & \\
\multirow{2}{*}{ Roots } & $\beta_{0}$ & 0.000010 & 0.000015 & 0.80 & 9.6435 & $<0.0001$ \\
& $\beta_{1}$ & 2.529000 & 0.259900 & & & \\
\hline
\end{tabular}

\subsection{Biomass Structure of Sample Stumps and Roots}

The mean total dry stump and root weight (range within parentheses) was $45 \pm 39(1-185) \mathrm{kg}$ and $14 \pm 16(0.2-87) \mathrm{kg}$, respectively (Table 3 ). Curves relating the dry masses of stump and roots to 
diameter are presented in Figure 2. The mean percentage \pm SD of the total dry weight (stump + roots) accounted for by the dry weight of stumps and roots was $76 \pm 11 \%(40-96)$ and $24 \pm 11 \%(4-54)$, respectively (Table 3). The mean dry matter as a percentage of fresh weight for stump and roots was $45 \pm 6 \%$ (37-86) and $42 \pm 6 \%$ (19-60). The mean basic density for the 72 sampled stumps was $0.333 \pm 0.045 \mathrm{~g} \mathrm{~cm}^{-3}$ and varied between 0.262 and $0.484 \mathrm{~g} \mathrm{~cm}^{-3}$; the value for roots was $0.313 \pm 0.045(0.218-0.480$; Table 5).

Figure 2. Dry mass per tree, $\mathrm{kg}$ tree ${ }^{-1}$, in relation to diameter at breast height (DBH; mm) of stump (-・) and roots $(--\times)$ for sample trees from poplar stands growing on abandoned farmland.

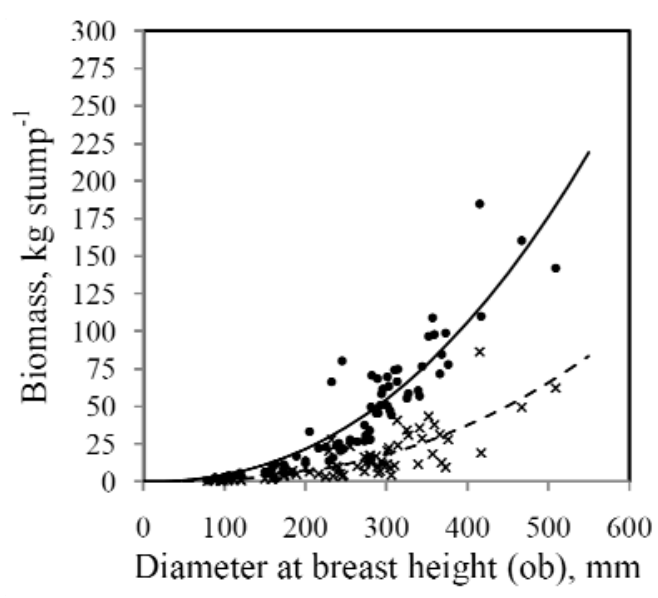

Table 5. Basic density, $\mathrm{g} \mathrm{cm}^{-3}$, for sampled poplar trees.

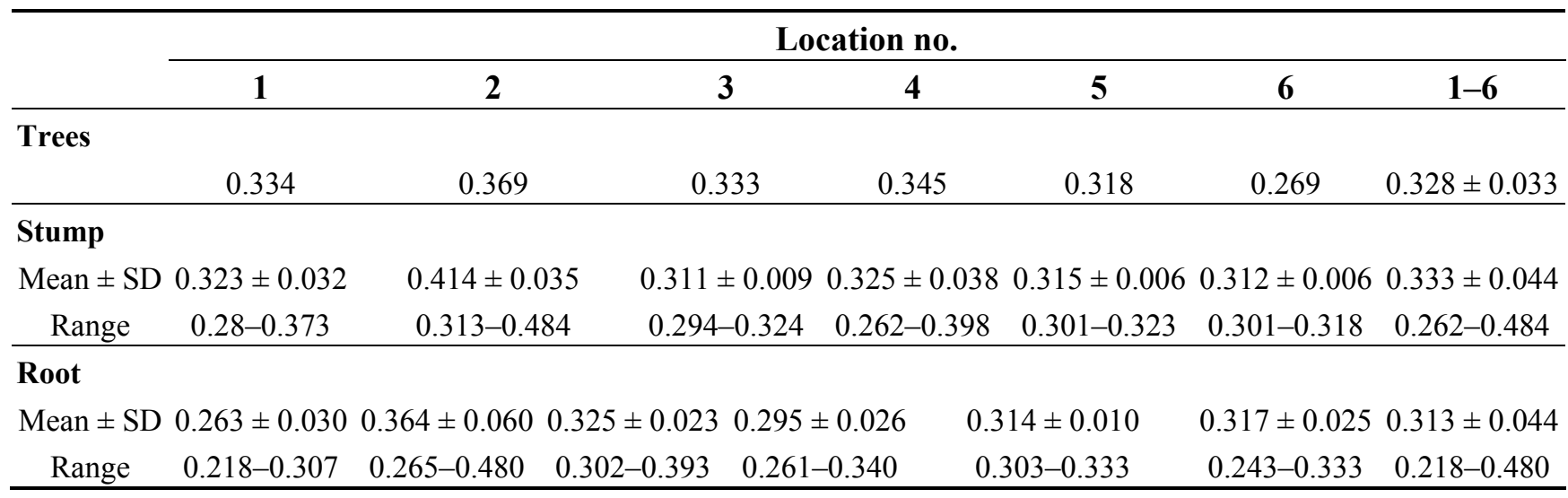

In an individual stump the mean length of all roots thicker than $50 \mathrm{~mm}$ was $6.71 \pm 4.68 \mathrm{~m}$ (0.1-21.93), of which 63,23 and $14 \%$ of the total root length was associated with root diameters of 50-100, 101-200 and >200 mm respectively. In Figure 3 the correlation between root length $(\mathrm{cm})$ and DBH is presented. The longest individual root was found for stems $\geq 500 \mathrm{~mm}$ (DBH). Percentage root weights for the corresponding root lengths were: $37 \%, 41 \%$ and $22 \%$ (Table 6 ). 
Figure 3. Relationship between root length $(\varnothing \geq 50 \mathrm{~mm})$ and diameter at breast height (ob), $\mathrm{mm}$.

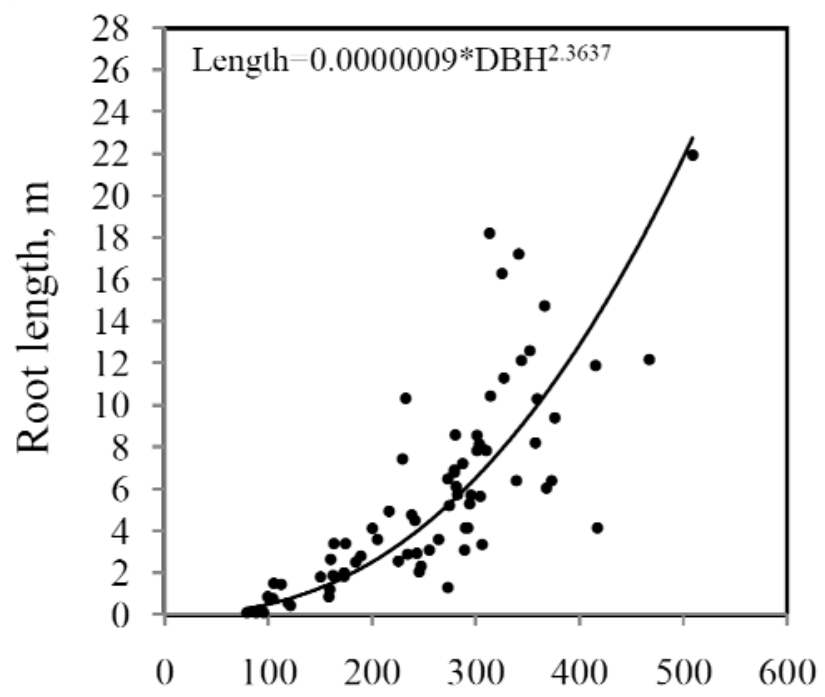

Diameter at breast height $(\mathrm{ob}), \mathrm{mm}$

Table 6. Mean root weight $(\mathrm{kg})$ and root length $(\mathrm{cm})$ of different root diameters $(\mathrm{mm})$ in poplar stands and mean percentage of total root weight and length.

\begin{tabular}{ccccccccc}
\hline Location & \multicolumn{4}{c}{ Root weight, kg d.w. } & \multicolumn{5}{c}{ Root length, cm } \\
\cline { 2 - 8 } no. \% & $\mathbf{5 0 - 1 0 0}$ & $\mathbf{1 0 1}-\mathbf{2 0 0}$ & $\mathbf{2 0 0}$ & Total & $\mathbf{5 0 - 1 0 0}$ & $\mathbf{1 0 1}-\mathbf{2 0 0}$ & $>\mathbf{2 0} \mathbf{~ c m}$ & Total \\
\hline 1 & $6.7 \pm 2.3$ & $14.8 \pm 10.9$ & $4.2 \pm 6.3$ & $25.7 \pm 17.3$ & $587 \pm 288$ & $221 \pm 252$ & $105 \pm 69$ & $913 \pm 540$ \\
$\%$ & 26 & 58 & 16 & - & 64 & 24 & 12 & - \\
2 & $2.9 \pm 1.6$ & $4.3 \pm 6.6$ & $0.3 \pm 0.5$ & $7.5 \pm 8.3$ & $225 \pm 153$ & $128 \pm 175$ & $20 \pm 0$ & $373 \pm 300$ \\
$\%$ & 39 & 57 & 4 & - & 60 & 34 & 6 & - \\
3 & $2.2 \pm 1.4$ & $0.1 \pm 0.3$ & $0 \pm 0$ & $2.3 \pm 1.6$ & $184 \pm 119$ & $60 \pm 33$ & $0 \pm 0$ & $244 \pm 137$ \\
$\%$ & 96 & 4 & 0 & - & 75 & 25 & 0 & - \\
4 & $8.8 \pm 6.9$ & $6.4 \pm 6.2$ & $9.8 \pm 14.5$ & $25.2 \pm 24.1$ & $693 \pm 518$ & $173 \pm 114$ & $154 \pm 44$ & $1020 \pm 681$ \\
$\%$ & 35 & 26 & 39 & - & 68 & 17 & 15 & - \\
5 & $6.5 \pm 1.1$ & $3.4 \pm 3.8$ & $1.7 \pm 2.6$ & $12.2 \pm 7.4$ & $451 \pm 168$ & $104 \pm 55$ & $75 \pm 30$ & $630 \pm 260$ \\
$\%$ & 54 & 32 & 14 & - & 71 & 17 & 12 & - \\
6 & $5.5 \pm 2.6$ & $7.6 \pm 4.4$ & $2.3 \pm 2.5$ & $15.4 \pm 8.4$ & $417 \pm 153$ & $167 \pm 62$ & $70 \pm 41$ & $653 \pm 231$ \\
$\%$ & 36 & 49 & 15 & - & 64 & 25 & 11 & - \\
\hline Mean \pm SD & $5.4 \pm 4.1$ & $5.9 \pm 7.5$ & $3.1 \pm 7.3$ & $14.4 \pm 15.6$ & $423 \pm 319$ & $155 \pm 153$ & $93 \pm 57$ & $671 \pm 468$ \\
Range & $0.2-23.7$ & $0.0-32.6$ & $0.0-51.6$ & $0.2-86.5$ & $10-1415$ & $0-940$ & $0-220$ & $10-2193$ \\
$\%$ & 37 & 41 & 22 & - & 63 & 23 & 14 & - \\
\hline
\end{tabular}

\subsection{Biomass Structure of Stumps and Roots at the Stand Level}

Actual mean dry mass production per hectare of the 12 sampled stump and root systems for the stands was calculated based on the stem number per hectare of each stand (Figure 4). The mean total dry mass of stump + roots was $46.9 \pm 30.0 \mathrm{t} \mathrm{ha}^{-1}$ (17.6-98.4) with $34.9 \pm 21.8$ (12.9-66.9) for stumps and $12.0 \pm 9.6(4.7-10.9)$ for roots. 
Figure 4. Total dry mass production $\left(\right.$ ton $\mathrm{ha}^{-1}$ ) for $\square$ stumps, $\square$ roots and $\boldsymbol{\square}$ stump + roots from six poplar stands on former farmland.

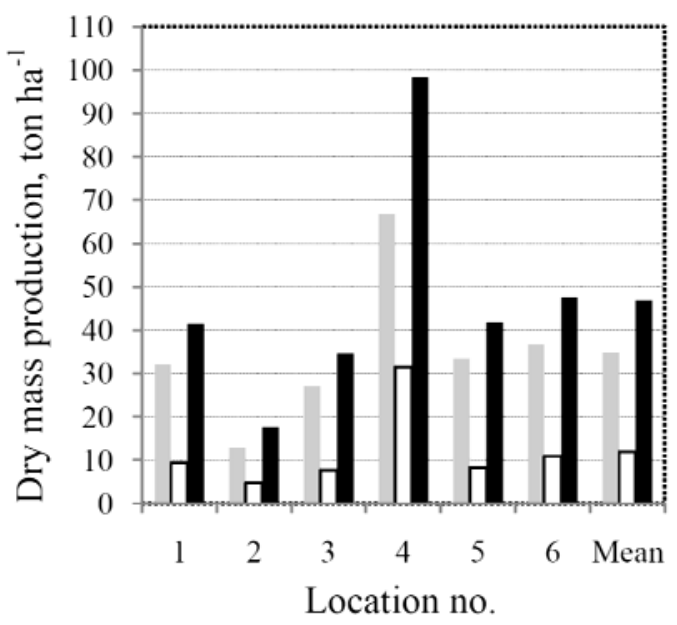

\section{Discussion}

When harvesting stumps using a conventional excavator, parts of the root system will also be included. In the present study most of the roots thicker than $50 \mathrm{~mm}$ came away with the stump when it was lifted. If the cleaning of the stump + roots $(\geq 50 \mathrm{~mm})$ is easy to manage the additional $6.5 \%$ of roots that can also be collected may provide extra revenue. However, soil type and soil moisture influence the time it takes to clean the stump and root system. The cleaning of stumps and roots growing in stands with a high percentage clay soil combined with a moist ground could be time-consuming and, hence, costly. These effects were observed during the study, especially in one of the stands. On the site with a moist light clay soil the roots were difficult to clean as the soil was firmly attached to the roots and between them. The percentage root length for 50-100 mm thick roots was $63 \%$ of the total. When harvesting the stump including roots $>100 \mathrm{~mm}$, the horizontal extent of roots removed decreased drastically when less attached soil was extracted with the stump. If it is possible to use excavators that only harvest the stumps and the coarsest roots $(>100 \mathrm{~mm})$, an additional $4 \%$ biomass might be added.

When choosing a suitable species or clone for commercial forestry, the level of basic density is an important factor. The basic density indicates the amount of dry weight solid wood by tree volume. Generally conifer species have higher basic density for stump wood than for stem wood: Young and Chase [17] found the mean basic density for the stump-root system of poplar was to be $0.336 \mathrm{~g} \mathrm{~cm}^{-3}$ compared to $0.381 \mathrm{~g} \mathrm{~cm}^{-3}$ for stems. In a Swedish study of planted poplars on former farmland [5] the basic density of stems was found to be $0.349 \pm 0.009 \mathrm{~g} \mathrm{~cm}^{-3}(0.269-0.470)$ compared with $0.313 \pm 0.044 \mathrm{~g} \mathrm{~cm}^{-3}(0.218-0.480)$ for roots in the present study. The sample of coarse roots used in the basic density analysis included two root diameters: 50-100 and 101-200 mm. The means were: $0.311 \pm 0.052$ and $0.315 \pm 0.044 \mathrm{~g} \mathrm{~cm}^{-3}$ respectively indicating higher values for thicker roots.

The data on stump biomass as a percentage of stem or total tree biomass indicate a promising supply of raw materials for producing bioenergy. The biomass from a poplar stump amounts to about $20 \%$ of the stem biomass $[18,19]$. In the present study, stump weight accounted for $21 \%$ and $6.5 \%$ for roots. Fang et al. [20] reported the belowground biomass as a percentage of total tree biomass of two 
poplar clones in China to be $20 \%$. In a study of an 8-year-old and a 9-year-old stand of Eastern cottonwood in India the belowground biomass was reported to be $18 \%$ as a percentage of total tree biomass [21] or $16 \%$ [22]. The dry weight of stump as a percentage of the stump-root system was $76 \%$ (40-96) in the present study. Ajit et al. [22] reported 58\% for a 9-year-old stand of Eastern cottonwood in India.

In the present study, the belowground biomass $\mathrm{ha}^{-1}$ (stump + roots) was directly related to the aboveground biomass $\mathrm{ha}^{-1}$. Puri et al. [23] reported a similar relationship between root biomass and aboveground biomass for Eastern cottonwood. They also found differences in coarse root $(>5 \mathrm{~mm})$ biomass $\mathrm{ha}^{-1}$ depending on spacing (2250, 531 and 208 stems ha $^{-1}$ ). The amount of coarse root biomass decreased as spacing increased. However in the present study no such relationship was found for the six stands with densities of $361,632,3279,1250,675$ and 707 stems ha $^{-1}$, and root biomass values of 9.4, 4.4, 6.6, 31.3, 8.1 and 10.6 tons $^{-1}$ respectively (Figure 4). The number of stems ha ${ }^{-1}$ has an influence on the area production values and a low biomass per individual in a dense stand might result in a high area biomass compared with a higher individual biomass in a stand with lower numbers of stems (Tables 1 and 3 ).

Poplar can be planted using a variety of methods: poles (2.0-3.0 m stout poles), stakes or wands $(0.75-1.0 \mathrm{~m})$, un-rooted cuttings $(0.4-0.5 \mathrm{~m})$ or rooted cuttings $(0.8-1.0 \mathrm{~m})$ [24]. If poplar poles are planted to a depth of $0.8 \mathrm{~m}$, a deep taproot forms [25]. In Italy these stumps are harvested using a special tool, which removes the stump and taproots without the lateral roots. The shape of a root system is determined by site conditions [26]. A shallow root system develops even in species that usually produce deep roots if the soil has a high water table. According to Köstler et al. [27] the root-system of poplar is shallow with a root length of up to $40 \mathrm{~m}$. In addition, Stokes and Mattheck [26] reported a shallow root system for poplar. In Sweden only rooted cuttings have been used to establish poplar plantations. Thus, the stumps did not have taproots and most of the lateral roots were found between 5 and $30 \mathrm{~cm}$ below ground level. The mean root length of the course ( $\geq 50 \mathrm{~mm}$ ) roots was $6.71 \mathrm{~m}$. In a study of Populus deltoides (Eastern cottonwood) the coarse root length was found to be 3.4-4.8 $\mathrm{m}$ [23]. They also reported that the maximum coarse root biomass was found in the top $30 \mathrm{~cm}$ of the soil profile. In a study by Faulkner [28] the root system of a Euro-American poplar clone was found between 5 and $20 \mathrm{~cm}$ below ground level and in a study of 12-year-old Veronese poplar (Populus deltoides $\times$ nigra) stands in New Zealand most of the coarse roots ( $\geq 2 \mathrm{~mm}$ ) were found within the top $40 \mathrm{~cm}$ of the soil profile [29].

\section{Conclusions}

The study focused on stump and coarse root $(\geq 50 \mathrm{~mm})$ estimations for poplar growing on former farmland. This is the first such data reported for Swedish conditions. Plantations of poplar in Sweden are about 20 years old and most of them are due to be cut. The owners are interested in alternatives for the future management of the area. One option is to remove the stumps and roots to allow future planting of cereals or trees. In the future, the biomass associated with stumps and roots may represent a valuable source of bioenergy and an economically important component of poplar forestry operations. Diameter at breast height $(\mathrm{DBH})$ was chosen as the parameter used to estimate biomass in stands before harvest. Diameter is a commonly used characteristic and is easy to record in a stand. Poplars in 
Sweden are planted as rooted cuttings (seedlings), which produce a shallow root system, making the stumps easier to harvest than those with a tap root. The mean dry weight of a poplar stump was $45 \mathrm{~kg}$, representing $21 \%$ of the stem dry weight. If roots $\geq 50 \mathrm{~mm}$ were included with the stump, the mean dry weight was $59 \mathrm{~kg}$ or $27 \%$ of the stem dry weight. This supply of biomass on stand level in addition to the aboveground part of a poplar is potentially of great interest. Based on data of the six studied stands the mean total biomass per hectare was 216 tons of which stumps + roots represented $22 \%$. A conventional excavator can lift the stump and parts of the root system without difficulty and at a low cost.

\section{Acknowledgements}

Helpful assistance was given by the owners (P.-O. Person; J. Kockum; B. Persson and I. Andersson). The excavation of stumps was made by five entrepreneurs. Linguistic revision was made by Sees-Editing Ltd UK. All of the above are gratefully acknowledged. Swedish Energy Agency provided financial support.

\section{Conflict of Interest}

The authors declare no conflict of interest.

\section{References}

1. FAO. Poplars and Willows in Wood Production and Land Use; Food \& Agriculture Organization: Rome, Italy, 1980.

2. Guzina, V.; Herpka, I.; Marinkovic, P.; Krstinic, A.; Bozic, J.; Vrataric, P. Poplars and Willows in Yugoslavia; Poplar Research Institute: Novi Sad, Yugoslavia, 1979.

3. Krauter, D.; Lewandowski, I.; Claupein, W. Quantity and quality of harvestable biomass from Populus short rotation coppice for solid fuel use-A review of the physiological basis and management. Biomass Bioenerg. 2003, 24, 411-427.

4. Rytter, L.; Johansson, T.; Karacic, A.; Weih, M. Orienterande Studie Om Ett Svenskt Forskningsprogram för Poppel; Skogforsk: Uppsala, Sweden, 2011.

5. Johansson, T.; Karačić, A. Increment and biomass in hybrid poplar and some practical implications. Biomass Bioenerg. 2011, 35, 1925-1934.

6. Verani, S.; Sperandio, G.; Picchio, R.; Spinelli, R.; Picchi, G. Field Handbook—Poplar Harvesting; Food and Agriculture Organization of the United Nations: Rome, Italy, 2008; pp. 27-34.

7. Hakkila, P. Utilization of Residual Fuel Biomass; Springer-Verlag: Berlin, Germany, 1989.

8. Andersson, E.; Tuimala, A. Definitioner, $\mathrm{mm}$, vid vedundersökningar (Definitions for wood technology); The Nordic Joint Group in Wood Technology Research Note No. 4; Joint Nordic Group for Wood Technology and Producers: Ås, Norway, 1980, pp. 53-66 (in Swedish).

9. Johansson, T. Biomass equations for determining fractions of European pendula and pubescent birches growing on abandoned farmland and some practical implications. Biomass Bioenerg. 1999, 16, 223-238. 
10. Ekström, G. Klassifikation av svenska åkerjordar (Classification of Swedish soil types on farmland); Serie C. Avhandlingar och Uppsatser, 3448476; Geological Survey of Sweden (SGU) (Sveriges Geologiska Undersökning): Stockholm, Sweden, 1929; pp. 1-161 (in Swedish).

11. Kittredge J. Estimation of the amount of foliage of trees and stands. J. For. 1944, 42, 905-912.

12. Payandeh, B. Choosing regression models for biomass prediction models. For. Chron. 1981, 57, 229-232.

13 Satoo, T.; Madgewick, H.A.I. Forest Biomass; Springer: Berlin, Germany, 1982; p. 23.

14. Bolstad, P.V.; Gower, S.T. Estimation of leaf area index in fourteen southern Wisconsin forest stands using a portable radiometer. Tree Phys. 1990, 7, 115-124.

15. SAS, Version 9.1; SAS Institute Inc.: Cary, NC, USA, 2006.

16. Zar, J.H. Biostatistical Analysis; Prentice Hall: Englewood Cliffs, NJ, USA, 1999.

17. Young, H.; Chase, A.J. Fiber Weight and Pulping Characteristics of the Logging Residue of Seven Tree Species in Maine; Maine Agricultural Experiment Station, University of Maine: Orono, ME, USA, 1965.

18. Richardson, J.; Björheden, R.; Hakkila, P.; Lowe, A.T.; Smith, C.T. Bioenergy from Sustainable Forestry: Guiding Principles and Practices; Kluwer Academic: Dordrecht, The Netherlands, 2002.

19. Shyam, S.; Srivastava, A.K. Biomass producing potential in age series of Populus deltoides plantation in Rohilkhand Region of Uttar Pradesh. Plant Arch. 2011, 11, 231-237.

20. Fang, S.; Xue, J.; Tang, L. Biomass production and carbon sequestration potential in poplar plantations with different management patterns. J. Environ. Manag. 2007, 85, 672-679.

21. Lodhiyal, L.S.; Singh, R.P.; Rana, B.S. Biomass and productivity in an age series of short rotation Populus deltoides plantations. Trop. Ecol. 1992, 33, 214-222.

22. Das, D.K.; Chaturvedi, O.P.; Jabeen, N.; Dhyani, S.K. Predictive models for dry weight estimation of above and below ground biomass components of Populus deltoides in India: Development and comparative diagnosis. Biomass Bioenerg. 2011, 35, 1145-1152.

23. Puri, S.; Singh, V.; Bhushan, B.; Singh, S. Biomass production and distribution of roots in three stands of Populus deltoides. For. Ecol. Manag. 1994, 65, 135-147.

24. Charlton, D.; McIvor, I.; Gawith, P.; Douglas, G. Growing Poplar and Willow Trees on Farms; National Poplar and Willow Users Group: Hamilton, New Zealand, 2007.

25. Spinelli, R.; Nati, C.; Magagnoti, N. Harvesting and transport of root biomass from fast-growing poplar plantations. Silva Fenn. 2005, 39, 539-548.

26. Stokes, A.; Mattheck, C. Variation of wood strength in tree roots. J. Exp. Bot. 1996, 47, 693-699.

27. Köstler, J.N.; Brückner, E.; Bibelriether, H. Die Wurzeln der Waldbäume; Verlag Paul Parey: Berling, Germany, 1968.

28. Faulkner, H.G. Root distribution, amount and development from 5-year-old Populus $\mathrm{x}$ euroamericana (Dode) Gunier. M.S. Thesis, University of Toronto: Toronto, ON, Canada, 1976.

29. McIvor, I.R.; Douglas, G.B.; Benavides, R. Coarse root growth of Veronese poplar trees varies with position on an erodible slope in New Zealand. Agrofor. Syst. 2009, 76, 251-264.

(C) 2012 by the authors; licensee MDPI, Basel, Switzerland. This article is an open access article distributed under the terms and conditions of the Creative Commons Attribution license (http://creativecommons.org/licenses/by/3.0/). 